\title{
Development of reading and writing skills of heritage Russian speakers in Cyprus
}

\author{
Sviatlana Karpava \\ University of Central Lancashire, Cyprus \\ https://doi.org/10.36505/ExLing-2018/09/0015/000348
}

\begin{abstract}
The present study is focused on language proficiency and literacy skills of RussianCypriot Greek bilingual children, Russian heritage speakers, children of the first generation immigrants living in Cyprus. Both cross-sectional and longitudinal methodology was implemented to investigate developmental trajectory, dominant language transfer, divergent attainment and attrition of L1 by Russian heritage speakers in Cyprus. Heritage speakers were measured on their reading and writing skills in Russian every month for a period of one year. Longitudinal data consists of the written corpus of dictations and oral corpus of reading aloud recordings. Overall, heritage children were better at reading than writing, comprehension than production. Their spelling and stress assignment errors are due to L1 transfer from Cypriot Greek.

Key words: Russian heritage speakers, reading, writing skills.
\end{abstract}

\section{Introduction}

Heritage speakers are bilinguals in home and dominant languages, they have more family or cultural motivation and connection to the former, minority or immigrant language, and are more proficient in the latter, society language (Polinsky and Kagan, 2007). The present study is focused on language proficiency and literacy skills of Russian-Cypriot Greek bilingual children, Russian heritage speakers, children of the first generation immigrants living in Cyprus. Both cross-sectional and longitudinal research methodology was implemented in order to investigate developmental trajectory, dominant language transfer, divergent attainment and attrition of L1 by Russian heritage speakers in Cyprus. The aim of this study is to examine whether Russian-CG children are balanced bilinguals, whether there is a difference between their perceptive and productive skills in both languages, Russian and CG, and which factors affect the development of their reading and writing skills.

\section{Study}

The participants were 39 simultaneous bilingual children (RussianCypriot Greek), 17 boys and 22 girls, born in Cyprus (father CG and mother Russian). Their dominant society language is Cypriot Greek,

ExLing 2018: Proceedings of 9th Tutorial and Research Workshop on Experimental Linguistics, 28-30 August, Paris, Frannce 
while their home (weak/minority) language is Russian. They have limited exposure to Russian, only at home, and low level of schooling in Russian, only 1-2 hours of Russian lessons per week, see Table 1.

Table 1. Bilingual children: Age, gender and school grade.

\begin{tabular}{|l|l|l|l|l|l|l|}
\hline $\mathrm{N}$ & School grade & Female & Male & Mean age & Range & SD \\
\hline 11 & $2^{\text {nd }}$ & 5 & 6 & $8 ; 8$ & $7 ; 7-9 ; 8$ & 0.7 \\
\hline 9 & $3^{\text {rd }}$ & 5 & 4 & $9 ; 9$ & $8 ; 11-12 ; 5$ & 1.4 \\
\hline 8 & $4^{\text {th }}$ & 4 & 4 & $10 ; 8$ & $9 ; 4-12 ; 0$ & 0.8 \\
\hline 11 & $5^{\text {th }}$ & 8 & 3 & $12 ; 12$ & $9 ; 5-14 ; 1$ & 1.3 \\
\hline \hline
\end{tabular}

Bilingual children, heritage speakers of Russian were measured regarding their reading and writing skills in Russian every month for a period of one year. Longitudinal data consists of the written corpus of dictations and oral corpus of reading aloud recordings. The participants were tested on a large battery of tests. Their language proficiency in Greek/CG and Russian were measured with the Developmental Verbal IQ Test (DVIQ), slightly adapted to CG from Stavrakaki and Tsimpli's (2000) SMG original and the Russian Proficiency Test for Multilingual Children (RPTMC) (Gagarina et al., 2010) respectively. Besides the tests, a detailed questionnaire (filled by parents) on language input situation, linguistic and extra-linguistic development of a child was used (Gagarina et al., 2010). Elicited and spontaneous oral production, in Russian and CG, obtained via elicited story-telling while describing eight sets of pictures (Tsimpli et al., 2005) was analysed in terms of speech rate (number of words per minute).

\section{Results and discussion}

The analysis of the data showed that bilingual children, heritage speakers of Russian had slightly better overall scores for DVIQ (70\%) than for RPTMC (68\%), perceptive skills than productive skills, nouns than verbs, see Tables 2-3.

Table 2. DVIQ Results.

\begin{tabular}{|l|l|l|l|}
\hline \hline DVIQ Greek: measures & Target production $\%$ & Mean & SD \\
\hline Total scores & 73.17 & 110.89 & 23.81 \\
\hline Lexicon production & 62.09 & 16.91 & 4.38 \\
\hline Morphosyntax production & 59.55 & 13.95 & 5.26 \\
\hline Morphosyntax comprehension & 78.17 & 26.26 & 7.44 \\
\hline $\begin{array}{l}\text { Comprehension of metalinguistic } \\
\text { concepts }\end{array}$ & 74.11 & 19.30 & 4.49 \\
\hline Sentence repetition & 82.72 & 43.70 & 5.64 \\
\hline \hline
\end{tabular}


The results of the speech rate analysis (number of words per minute), based on oral production revealed that bilingual Russian-CG children had a higher speech rate in CG (Mean 53.39, range 19-84, SD 15.93) in comparison to Russian (Mean 38.3, range 25-65, SD 15.12).

Table 3. Russian Language Proficiency Test Results.

\begin{tabular}{|l|c|c|c|}
\hline RLPTMC: measures & Target production \% & Mean & SD \\
\hline Production Lexicon: nouns & $64.38 \%$ & 16.73 & 5.53 \\
\hline Production Lexicon: verbs & $54.68 \%$ & 14.21 & 5.02 \\
\hline Production : case & $55.79 \%$ & 3.34 & 2.20 \\
\hline Perception: grammatical constructions & $71.54 \%$ & 15.73 & 2.91 \\
\hline Production: verbal inflection & $81.88 \%$ & 9.82 & 2.16 \\
\hline Perception lexicon: nouns & $80.43 \%$ & 8.04 & 1.55 \\
\hline Perception lexicon: verbs & $76.95 \%$ & 7.69 & 1.63 \\
\hline
\end{tabular}

According to Pearson correlation statistical analysis (Sig. 2-tailed), age is correlated with RPTMC (.007); DVIQ (.007) and speech rate (.004). School grade - with DVIQ (.006), RPTMC (.003) and speech rate (.012). Regarding the analysis of reading skills development of bilingual children, in particular reading speed: words per minute (WPM): a measure of words processed in a minute, it was revealed that there is an overall increase in their reading speed (mean scores) from the $2^{\text {nd }}$ to the $5^{\text {th }}$ grade, see Figure 1.

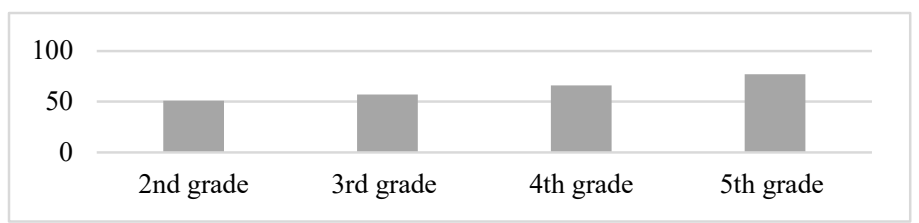

Figure 1. Reading speed: word per minute (WPM).

Stress errors of bilingual Russian-CG children are only within finalpenultimate-antepenultimate syllables range (e.g., ножи 'knives' instead of

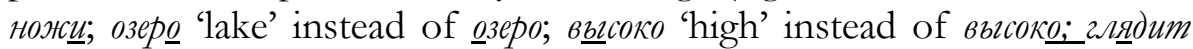
'looks' instead of zляdum; пески 'sands' instead of пескu). This could be due to L1 transfer from CG. The analysis of the dictations with respect to orthography and spelling errors showed that there is a developmental pattern: bilingual children produce fewer errors with more input and training, see Figure 2. 


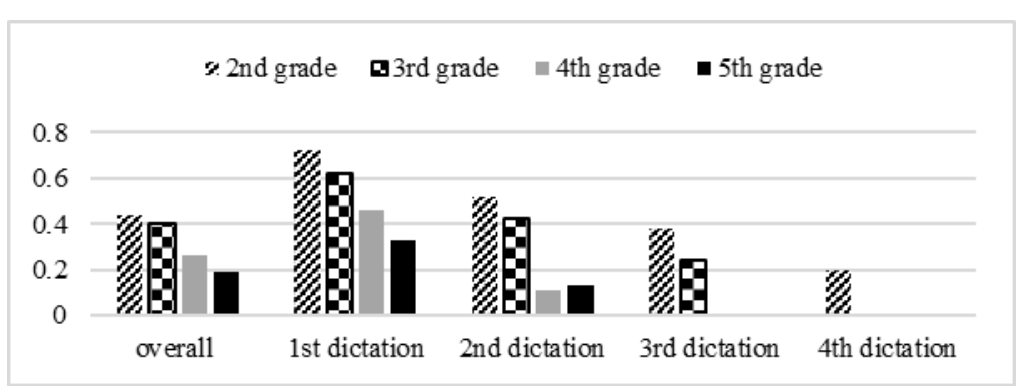

Figure 2. Dictations: Number of errors/number of words ratio.

Bilingual children had spelling errors mainly in the stem $(58 \%)$ or in the ending $(42 \%)$ of the word. They had more substitution errors $(82 \%)$ than omission errors (18\%); vowels $(63 \%)$ than consonants $(37 \%)$,

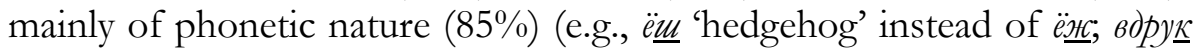
'suddenly' instead of вдpyz; ucnyzanca 'he got afraid' instead of ucnyzanc무 листия 'leaves' instead of листьия; решицла 'she decided' instead of pemuла). According to Pearson correlation statistical analysis (Sig. 2-tailed), reading speed is correlated with overall dictation errors (.000). School grade - with reading speed (.005) and overall dictation errors (.000). Age — with reading speed (.003) and overall dictation errors (.000). The results of the study showed that bilingual children in Cyprus have higher scores for perceptive skills than productive skills. They show a developmental pattern with age and school exposure for production and receptive skills, reading and writing skills. The gap between comprehension and production in bilingual children can be due to the bilingualism effect. More research is needed to inform the parents and the authorities about the importance of a balanced bilingual development of a child, without forgetting a heritage or a minority language.

\section{References}

Gagarina, N., Klassert, A., Topaj, N. 2010. Sprachstandstest Russisch für mehrsprachige Kinder [Russian language proficiency test for multilingual children]. ZAS Papers in Linguistics 54.

Polinsky, M., Kagan, O. 2007. Heritage Languages: In the "wild" and in the classroom. Language and Linguistics Compass 1, 368-395.

Stavrakaki, S., Tsimpli, I. 2000. Diagnostic verbal IQ test for Greek preschool and school age children: Standardization, statistical analysis, psychometric properties. Proceedings of the $8^{\text {th }}$ Symposium of the Panhellenic Association of Logopedists, 95106. Athens: Ellinika Grammata.

Tsimpli, I., Roussou, A., Fotiadou, G., Dimitrakopoulou, M. 2005. The syntax/morphology Interface: Agree Relations in L1 Slavic/L2 Greek. Proceedings of the $7^{\text {th }}$ International Conference on Greek Linguistics 1-15. University of York. 